\title{
Reflective thinking, effort, persistence, disorganization, and academic performance: A mediational approach
}

\author{
Huy P. Phan
}

School of Education, University of New England, Armidale

\section{Australia}

Correspondence: Huy P. Phan. Senior Lecturer in Learning and Teaching/Educational Psychology.

School of Education, Faculty of the Professions. Armidale, NSW 2351. Australia. E-mail: hphan2@une.edu.au

(C) Education \& Psychology I+D+i and Editorial EOS (Spain) 


\begin{abstract}
Introduction: This article reports on a two-phase study that was conducted looking at study processing strategies, reflective thinking practice, and academic performance. Phase 1 is a meditational analysis of a conceptual model that we have developed involving examination of direct and mediating effects between the four phases of reflection (habitual action, understanding, reflection, and critical thinking) and academic performance, mediated by disorganization, persistence, and effort. Phase 2 involved a logistic regression analysis that examined students' engagement in reflective thinking practice and their effort expenditure.
\end{abstract}

Method: Three hundred and four (131 females, 173 males) university students were administered a package of Likert-type inventories (e.g., The Reflective Thinking Questionnaire) in tutorial classes.

Results: Results from Phase 1 indicated the importance of the understanding and reflection phases and persistence as direct determinants of academic performance. Persistence also acted as a mediator between the reflection phase and academic performance. From Phase 2, logistic regression analysis showed that students' engagement in critical thinking led to effort expenditure in learning.

Discussion or Conclusion: In conclusion, the conceptual model and subsequent findings established in this study make theoretical and practical contributions to the literature concerning the direct-mediating mechanism between reflective thinking practice, disorganization, persistence, effort, and academic performance

Keywords: Study processing strategies, reflective thinking, disorganisation, meditational process

Received: 03/06/09 Initial Acceptance: 03/13/09 Final Acceptance: 07/09/09 


\section{Pensamiento reflexivo, persistencia, desorganización y ejecución académica: un enfoque mediacional}

\section{Resumen}

Introducción: Este artículo presenta un estudio de dos fases enfocado a las estrategias de estudio de procesamiento, la práctica de la reflexión y la ejecución académica. La fase 1 es un análisis mediacional del modelo conceptual que se ha desarrollado involucrando la evaluación directa y mediante efectos entre las cuatro fases de la reflexión (acción habitual, comprensión, reflexión y pensamiento crítico) y la ejecución académica, mediado por la falta de organización, grado de persistencia y esfuerzo. La fase 2 conlleva un análisis de regresión logística que valoran la implicación de los estudiantes en la práctica de la reflexión y el costo del esfuerzo.

Método: Trescientos cuatro (131 mujeres y 173 hombres) estudiantes universitarios cumplmentarion un conjunto de instrumentos tipo Likert (p.e. Cuestionario sobre Pensamiento Reflexivo) durante las horas de tutoría.

Resultados: Los resultados de la fase 1 indicaron la importancia de las fases de comprensión y reflexión, y de la persistencia cómo determinantes directos de la ejecución académica. De la fase 2, el análisis de regresión logística muestra que la implicación de los estudiantes en la reflexión dirige el costo del esfuerzo para aprender.

Discusión y conclusiones: En definitiva, el modelo conceptual y los subsiguientes hallazgos establecen en este estudio proporcional una contribución teórica y práctica a la literatura relacionada con los mecanismos de mediación directa entre la práctica del pensamiento reflexivo, la falta de organización, la persistencia, el esfuerzo y la ejecución académica.

Palabras Clave: Estrategias de procesamiento, pensamiento reflexive, falta de organización y proceso mediacional

Recibido: 06/03/09 Aceptación inicial: 13/03/09 Aceptación final: 09/07/09 


\section{Introduction}

Educational research has recently involved the study of reflection and how this practice influences the teaching and learning processes. Reflection, or what is commonly referred to as "reflective thinking" has been widely researched with preservice students and inservice teachers in the context of teaching and learning (Grushka, McLeod, \& Reynolds, 2005; Harrison, Lawson, \& Wortley, 2005; Pedro, 2005). Existing research studies employing different methodological approaches have provided evidence to indicate that reflection is beneficial as it enables students and educators alike to think critically about their own learning and professional development (Grushka et al., 2005; Leung \& Kember, 2003; Phan, 2009; Yanchar, Slife, \& Warne, 2008). The ultimate outcome of reflection is the development of specific skills that may assist individuals to become more critical and to develop expertise in their areas of professionalism. More recently, researchers have used latent variables analyses to explore how reflective thinking practice relates to students' self-efficacy beliefs, effort, achievement goals, and study processing strategies (Leung \& Kember, 2003; Mezirow, 1991, 1998; Phan, 2007, 2008a).

Within the motivational domain, research investigation has also explored three constructs that are central to the prediction of academic performance - disorganization, effort, and persistence (Elliot, McGregor, \& Gable, 1999; Fenollar, Román, \& Cuestas, 2007; Phan, 2009). The evidence suggests that there is a clear relationship between effort and persistence and academic performance (Bouffard, Boisvert, Vezeau, \& Larouche, 1995; Elliot et al., 1999; Wentzel, 1996), whereas much less is clear and known about disorganization and its effect on learning outcome (Al-Emadi, 2001; Elliot et al., 1999). The mediating processes of effort, persistence, and disorganization, as reported in Elliot et al.'s study, indicate the important indirect influences of other motivational constructs (e.g., achievement goals) on academic performance. In this article we present a quantitative study that involves two sequential phases: Phase 1 is a direct-mediating analysis of a conceptual model that we have developed based on existing research evidence; and Phase 2 is a logistic regression analysis that involves the relationship between reflective thinking and effort expenditure. The conceptual framework for Phase 1 involves reflective thinking and how this construct combines with effort, persistence, and disorganization to influence academic performance. To date, the literature does not 
present research to validate the relationships between reflective thinking and/or effort, persistence, and disorganization. Specifically, the research questions addressed in this study are:

RQ1: What are the effects of reflective thinking practice on academic performance, either direct or mediated by effort, disorganization, and persistence?

RQ2: What is the contribution of effort, disorganization, and persistence to predicting academic performance?

RQ3: Do students more likely to report on effort expenditure when engaging in reflective thinking practice?

\section{Reflective thinking as predictor of academic performance}

The notion of reflection may be credited to the work of John Dewey (1933), who defined it as "active, persistent, and careful consideration of any belief or supposed form of knowledge in the light of the grounds that support it and the conclusion to which it tends" (p. 9). Furthermore reflective thinking, as outlined in his original writing, encompasses two important aspects. "Reflective thinking, in distinction from other operations to which we apply the name of thought, involves (1) a state of doubt, hesitation, perplexity, mental difficulty, in which thinking originates, and (2) an act of searching, hunting, inquiring, to find material that will resolve the doubt, settle and dispose of the perplexity." (Dewey, 1993, p. 12). More importantly, however, Dewey advocated the distinctive difference between critical reflection and reflection: an individual who is not sufficiently critical may reach a hasty conclusion without examining all the possible outcomes (Leung \& Kember, 2003).

The practice of reflection has expanded empirically to encompass the work of Jack Mezirow $(1991,1998)$ involving the theoretical premise of transformative education. Leung and Kember (2003), based on this contention, advocate that reflective thinking may be categorised into four distinct phases; in their order of importance - habitual action, understanding, reflection, and critical thinking. Habitual action is a mechanical and automatic activity that is performed with little thought or consciousness. Understanding is learning and reading without relating the contents to other situations. Reflection concerns active, persistent and careful considerations of any assumptions or beliefs grounded in our consciousness. Finally, critical thinking is considered as a higher level of reflective thinking that involves us becoming more aware of why we perceive things, the way we feel, act and do. 
Research pertaining to the four phases of reflection has provided empirical evidence attesting to the underlying structure the four phases, as well as their associations with academic performance outcome. The original work of Leung and Kember (2003) with Hong Kong students, in particular, has been salient in exploring the four phases of reflection (Mezirow, 1991, 1998). Using confirmatory factor analysis (CFA), Leung and Kember found items descriptive of the four phases - habitual action, understanding, reflection, and critical thinking represented four distinct latent dimensions. In accord with this evidence, Phan's studies involving Pacific and Indo-Fijian tertiary students have been instrumental in helping to explain the relationship between the four phases of reflection and academic performance. In this analysis, habitual action and understanding are found to relate negatively to academic performance (Phan, 2007, 2008a), whereas reflection and critical thinking positively predict academic performance (Phan, 2008a, 2009). This associative alignment between the four phases of reflection and academic performance, however, may be explained within the context of teaching pedagogies, learning objectives, and assessment criteria and outcome (Biggs, 1999; Phan, 2007). In addition to this empirical pattern, other motivational constructs (including self-efficacy, student approaches to learning, achievement goals, effort) examined in these studies also verified the predictive and concurrent validity of the four phases of reflection.

The importance of the four phases of reflection as mediators is also defined from the preliminary evidence established recently. Path analytical procedures involved in examination of the four phases of reflection (Leung \& Kember, 2003; Mezirow, 1991, 1998) show that particular reflective thinking phases - for example, habitual action, understanding, and reflection - act as mediators between learning approaches, study strategies, goal orientations (e.g., mastery, performance) and academic performance (Phan, 2007, 2008a). According to this inquiry then, is the notion that reflection operates in a system where it acts as a determinant as well as a mediator of future performance outcomes.

\section{Effort, persistence, and their relation with disorganization}

Within the motivational domain, we focused on three constructs in this study - effort, persistence, and disorganization. Effort refers to the overall amount of effort expended in the process of studying (Zimmerman \& Risemberg, 1997), and persistence, also known as effort management or effort regulation (Pintrich, 1989; Pintrich, Smith, Garcia, \& McKeachie, 1993), is concerned with a continuing investment in learning even when obstacles are encoun- 
tered. A number of researchers have, in the context of achievement goals explored the contribution of persistence and effort in students' academic learning. Research evidence shows that effort and persistence make a positive contribution to the prediction of academic performance outcome (Bouffard et al., 1995; Miller, Greene, Montalvo, Ravindran, \& Nichols, 1996; Wentzel, 1996). In this analysis, both effort and persistence are found to relate positively to academic performance (Dupeyrat \& Mariné, 2005; Simons, Dewitte, \& Lens, 2004). Data drawn from other studies have shown the interrelations between efforts and persistence and other motivational variables; for example, disorganization (Elliot et al., 1999), study processing strategies (Dupeyrat \& Mariné, 2005; Fenollar et al., 2007), competence beliefs and utility (Chouinard, Karsenti, \& Roy, 2007), and reflection (Phan, 2008a). For example, Chouinard et al. (2007) found that competence beliefs act as a determinant of effort, whereas Simons et al. (2004) reported that task orientation contributes to the prediction of persistence. The work of Phan (2008a), in contrast, indicated that effort makes a direct contribution to the prediction of deep processing strategies and reflection.

Disorganization, as a motivational construct, refers to the difficulty that students face in establishing or maintaining a structured, organised approach to studying (Entwistle, 1988). Similar to the theoretical orientations of effort and persistence, disorganization has been researched in the context of achievement goals. Elliot et al.'s (1999) study with college students indicates that disorganization in learning exerts a negative effect on academic performance. Furthermore, disorganization acts as a potent mediator between achievement goals (e.g., performance-avoidance) and academic performance. Analysis of evidence suggests that performance-avoidance goals act as determinants of disorganization. Despite the strong emphasis in disorganization, very few research studies have explored this construct in relation to students' academic learning. Other research studies have, however, studied similar related constructs such as organising (Biggs, 1987) and time and study environment management (Pintrich et $a l .$, 1993). The limited research at present forms the premise for us to extend this line of inquiry and to explore how, in conjunction with effort and persistence, disorganization contributes to academic learning.

\section{Overview of the Present Study}

The present study attempts to explore within one conceptual framework the interrelations between the four phases of reflection (Leung \& Kember, 2003; Mezirow, 1991, 1998), 
effort, persistence, disorganization, and academic performance. Previous empirical studies have provided us with a premise to extend this line of inquiry concerning how, in totality, the described theoretical orientations operate in a teaching and learning system. The two individual strands of research inquiry, namely effort, persistence, and disorganization $\rightarrow$ academic performance (Bouffard et al., 1995; Elliot et al., 1999; Miller et al., 1996) and reflection $\rightarrow$ academic performance (Phan, 2007, 2008a), are integrated into one conceptual model that advocates effort, persistence, and disorganization as potential mediators between the four phases of reflection and academic performance.

This research study encompasses two phases. Phase 1 presents a path analysis examination of a conceptual model that we have developed, as shown in Figure 1. Consistent with previous evidence and based on our own theoretical understanding, the following four hypotheses are made:

H1: Habitual action will exert a positive effect on disorganization, and negative effects on persistence and effort. In contrast, the other three phases of reflection will exert negative effects on disorganization, and positive effects on persistence and effort.

H2: Disorganization will exert a negative effect on academic performance, whereas effort and persistence will exert positive effects on academic performance (e.g., Dupeyrat \& Mariné, 2005; Elliot et al., 1999; Simons et al., 2004).

H3: Habitual action will exert a negative effect on academic performance, whereas understanding, reflection, and critical thinking will exert positive effects on academic performance (e.g., Phan, 2007, 2008a).

H4: Disorganization, effort, and persistence will operate as mediators between the four phases of reflection and academic performance (Elliot et al., 1999). 


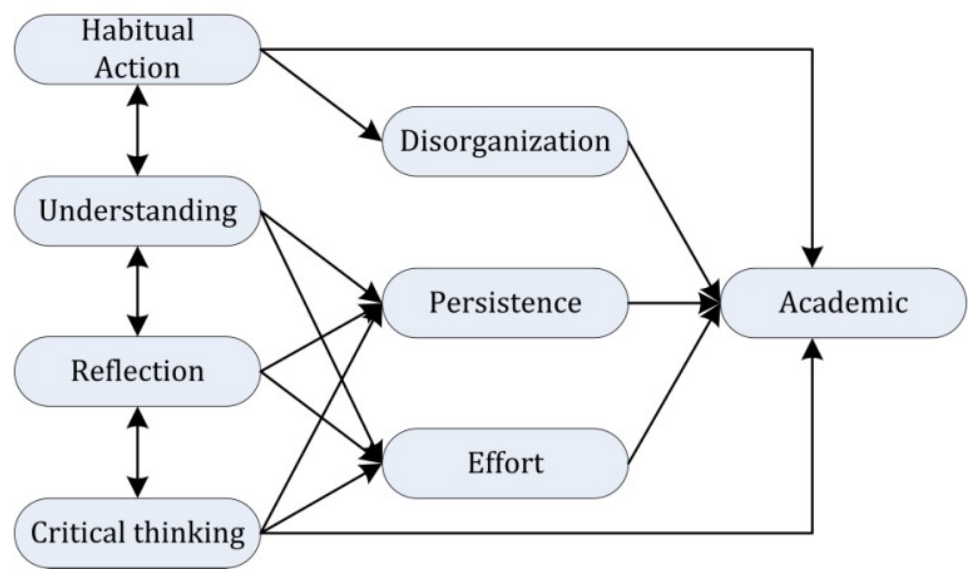

\section{Figure 1. A conceptual model of reflection, disorganization, persistence, effort, and academic performance.}

This phase of the research stems from a number of factors. First, there have been very few research studies that have looked at the validation of the four phases of reflective thinking practice as possible antecedents of various motivational constructs. Previous research has found that various motivational constructs, such as self-efficacy, study processing strategies, effort, and achievement goals act as determinants of the four phases of reflective thinking (Phan, 2007, 2008a). The four reflective thinking phases, in turn, are found to predict students' academic performance. Our conceptualisation in this study differs from existing evidence and advocates, in contrast, the plausibility that the four phases of reflective thinking may serve as antecedents of effort, persistence, and disorganization. Potential evidence established in this study would provide a stronger basis for further research investigation into cause-and-effect relationship using longitudinal data. Given the theoretical grounding of the four phases of reflection (Leung \& Kember, 2003; Mezirow, 1991, 1998) and previous evidence (Phan, 2007, 2008a), we postulate that habitual action would exert a positive effect on disorganization and negative effects on persistence and effort; likewise, the other three phases of reflection would exert positive effects on persistence and effort, and negative effects on disorganization. Habitual action, as a basic form of reflection, involves simply recollection and memorisation, and the ability to recall information automatically. Students who have this mindset are more likely to face problems when they attempt to organize their study habits. In contrast, understanding, reflection, and critical thinking involve complex analyses in articulation, reflection, and hypothesis of new knowledge. This engagement is more likely to lead students to persist and spend more time and effort in order to acquire these skills. 
Second, there is limited research at present concerning the mediating mechanism of disorganization and, to an extent effort and persistence. In this analysis, more research is needed to explore the role of disorganization as a potential mediator between the habitual action phase and academic performance. The work of Elliot et al. (1999) has been instrumental in helping to establish some theoretical support for the mediating roles of effort, persistence, and disorganization. The evidence established in Elliot et al.'s study indicated, for example, that disorganization mediated between performance-avoidance goals and students' academic performance outcomes. The mediating role of disorganization, effort, and persistence may be further verified by exploring these three constructs within the theoretical framework of reflective thinking practice. In our analysis, we state the direct contribution of habitual action on academic performance, indirectly mediated by disorganization (i.e., habitual action $\rightarrow$ disorganization $\rightarrow$ academic performance). Similarly, persistence and effort are advocated to act as mediators between the understanding, reflection, and critical thinking phases acting on academic performance (e.g., understanding $\rightarrow$ persistence $\rightarrow$ academic performance).

Phase 2 of this research study is concerned with the question of whether students who engage in understanding, reflection, and critical thinking would report more effort expenditure in their studying. In this analysis, the pertaining issue under investigation emphasises the possibility that understanding, reflection, and critical thinking may help students in their effort expenditure. This line of inquiry is based, in part, on previous theoretical contentions. It is possible, for example, to find students who articulate and reflect to report more willingness to expend effort in schoolwork, etc.

In conclusion, research findings pertaining to relationships between effort and persistence and academic performance are consistent and clear. Similarly, it would seem that the evidence concerning the four phases of reflection and academic performance is logical and in accordance with existing theoretical contentions. Much less is known, however, about the four reflective thinking phases and effort, persistence, and disorganization. Similarly, very little is known about the mediating mechanism that may exist between the four reflective thinking phases and academic performance, via disorganisation, persistence, and effort. The evidence that we obtain from this study may help to strengthen and elucidate the status concerning how these four theoretical frameworks (reflective thinking practice, effort, persistence, and disorganization) operate in a larger teaching and learning system. 


\section{Method}

\section{Participants}

Participants in the present study were 304 (131females, 173 males) first-year Liberal Arts and Science students enrolled in Psychology at a local medium size university. Instruments ${ }^{1}$ were administered in tutorial classes with the assistance of a tutor. Participation by the students was voluntary, and no remuneration was provided. Participants were instructed to write down their student number for the purpose of collecting performance marks in their individual courses. Students were assured of anonymity and it was explained why their overall performance marks were needed.

\section{Instrumentation}

Each participant was given an information booklet that contained a questionnaire with items descriptive of effort, disorganization, persistence, and reflective thinking practice. Participants were required to respond on a seven-point Likert-type rating scale; for example: 1 (strongly disagree) to 7 (strongly agree)(for reflective thinking practice and effort); and 1 (not at all true of me) to 7 (very true of me)(for persistence). Reflective thinking was measured using a 16-item scale developed by Kember, Leung, Jones, Loke, McKay, Sinclair, Tse, Webb, Wong, Wong, \& Yeung (2000). Disorganization was measured by five items and persistence was measured by four items from Elliot et al.'s (1999) scales. Effort was measured using three items from Elliot et al. (1999) and two items from the MSLQ (Pintrich et al., 1991).

Finally, academic performance was measured by collating continuing course work $(50 \%)$ and the overall final exam (50\%). at the end of the semester. Of the 50\% coursework $10 \%$ is allocated to workshop activities that include six written group reports based on set questions relating to the week's themes and readings and a group seminar. The remaining balance of the coursework is made up of a $20 \%$ individual school-based research project and a $20 \%$ mid-semester test. The workshops, comprising 25 students, are divided further into 'small work groups' of four or five for peer group activities and seminar presentations. Workshop instructors take into consideration gender and ethnic mix when forming the small work group with the aim of bringing various experiences and contexts to the course. 
In general, questions on the final exam were structured to elicit more than just recall of factual information. The composition of the final exam consisted of different formats (e.g., 10 True/False statements; 25 multiple-choices with four possible choices for each question; 10 short-answer questions; and one essay). Exam questions include, for example, 'How does your culture fit in with your understanding of Bronfenbrenner's bioecological theory of development?' and 'From your personal experience, give clear examples to indicate how Kohlberg's stages of morality take place'.

Reliability estimates (Cronbach's alpha) were .76 for the effort scale (e.g., "I put a lot of effort into preparing for the exam"), .91 for the disorganization scale (e.g., "I'm not sure how to study for this course"), .89 for the persistence scale (e.g., "When I become confused about something I'm reading for this course, I go back and try to figure it out"), .82 for the habitual action scale (e.g., 'In this course we do things so many times that I started doing them without thinking'), .83 for the understanding scale (e.g., 'To pass this course you need to understand the content'), .87 for the reflection scale (e.g., 'I often re-appraise my experience, so I can learn from it and improve for my next performance'), and .80 for the critical thinking scale (e.g., 'This course has challenged some of my firmly held ideas').

\section{Results}

Phase 1: Direct and mediating effects

Multiple and hierarchical regression analyses were used to examine the hypothesized direct and mediating relationships. Descriptive statistics and non-zero correlations for the variables under investigation are presented in Table 1.

\footnotetext{
${ }^{1}$ Permission was granted by the course/program coordinator to administer the questionnaire in tutorial classes.
} 
Table 1. Correlational matrix between the dependent and independent variables

\begin{tabular}{lcclllllll}
\hline & M(SD) & HA & U & R & CR & PE & EF & DI & ACA \\
\hline HA & $5.83(1.08)$ & 1.0 & & & & & & & \\
U & $5.71(1.45)$ & -.10 & 1.0 & & & & & \\
R & $5.51(1.44)$ & .03 & $.23^{* *}$ & 1.0 & & & & \\
CR & $5.01(1.15)$ & $.16^{* *}$ & .03 & $.23^{* *}$ & 1.0 & & & \\
PE & $5.52(1.68)$ & $-.11^{*}$ & $.51^{* *}$ & $.33^{* *}$ & .02 & 1.0 & & \\
EF & $4.84(1.27)$ & .08 & $.14^{*}$ & $.39^{* *}$ & $.56^{* *}$ & $.17^{* *}$ & 1.0 & \\
DI & $5.69(1.01)$ & $.32^{* *}$ & -.06 & .11 & $.26^{* *}$ & -.09 & $.12 *$ & 1.0 & \\
ACA & $19.37(4.02)$ & -.02 & $.24^{* *}$ & $.30^{* *}$ & .08 & $.29^{* *}$ & .09 & -.02 & 1.0 \\
\hline
\end{tabular}

Note: $\mathrm{HA}=$ habitual action, $\mathrm{U}=$ understanding, $\mathrm{R}=$ reflection, $\mathrm{CR}=$ critical thinking, $\mathrm{DI}=$ disorganization, $\mathrm{PE}=$ persistence, $\mathrm{EF}=$ effort, $\mathrm{Aca}=$ academic performance. Note: $* p<.05, * * p<.01$.

Hypothesis 1: The four phases of reflection to disorganization, persistence, and effort.

The regression of disorganization on the basic model (adjusted $R^{2}=.15, p<.0005$ ) revealed a significant positive relationship for habitual action $(\beta=.29, p<.0005)$ and critical thinking $(\beta=.21, p<.0005)$ but not for understanding or reflection. The regression of persistence on the basic model (adjusted $R^{2}=.31, p<.0005$ ) revealed significant positive relationships for understanding $(\beta=.46, p<.0005)$ and reflection $(\beta=.23, p<.0005)$. Regressing effort on the basic model (adjusted $R^{2}=.38, p<.0005$ ) yielded a significant positive relationship for reflection $(\beta=.26, p<.0005)$ and critical thinking $(\beta=.49, p<.0005)$.

Hypothesis 2: Disorganization, persistence, and effort to academic performance. Controlling for the effects of the four phases of reflection, academic performance was regressed on disorganization, persistence, and effort. Persistence (adjusted $R^{2}=.13, p<.0005$ ) was related positively to academic performance $(\beta=.16, p<.05)$, whereas there was no statistically significance for disorganization or effort.

Hypothesis 3: The four phases of reflection to academic performance. The regression of academic performance on the basic model (adjusted $R^{2}=.11, p<.0005$ ) yield significant relationships for understanding $(\beta=.18, p<.005)$ and reflection $(\beta=.26, p<.0005)$, but not habitual action or critical thinking.

Hypothesis 4: Mediating analyses between the four phases of reflection, disorganization, persistence, effort, and academic performance. We assessed the potential mediation of disorganization, persistence, and effort using Kenny's (2008) four-step model. According to this model, based on Baron and Kenny's (1986) and Judd and Kenny's (1981) earlier studies, 
mediation is established when the following criteria are met: (i) the independent variable (IV) is correlated with the dependent variable or outcome (DV), (ii) the IV is correlated with the proposed mediator, (iii) the proposed mediator affects the outcome variable, and (iv) combining the proposed mediator and the IV as predictors of the DV, the influence of the proposed mediator remains significant, whereas the influence of the IV is reduced (Montoya \& Horton, 2004, pp. 700-701). If these four criteria are met, then the data are consistent with the hypothesis that the proposed mediator completely mediates the IV-DV relationship.

The results from the first three hypotheses indicated that the first three mediation conditions are satisfied for persistence as a possible mediator between understanding and reflection and academic performance. The test of the indirect effect between understanding, persistence, and academic performance using Sobel's (1982) test yielded a test statistics of 2.40, $p=$ .016. The fact that the observed $p$ value fell below the established alpha level of .05 indicates that the association between the IV (understanding) and DV (academic performance) is reduced significantly by the inclusion of the mediator, in this case persistence, in the model. In other words, there is evidence of mediation. Likewise, the Sobel test indicated a test statistics of 2.20, $p=.027$ for the mediating relation between reflection, persistence, and academic performance. When the four phases of reflection, disorganization, persistence, and effort were included simultaneously as predictors of academic performance, the effect of reflection on academic performance was reduced $(\beta=.22, p<.0005)$ whereas the influence of persistence on academic performance remained statistically significant.

Given the documented mediation effects between understanding, reflection, persistence, and academic performance, a supplementary structural equation modelling (SEM) analysis was also conducted to examine the fit of the meditational model. In this analysis, we used covariance matrix with maximum likelihood estimation. In accord with existing theoretical positioning (Chou \& Bentler, 1995; Hoyle \& Panter, 1995), both absolute and incremental fit indexes (chi-square, comparative fit index (CFI), adjusted goodness-of-fit index (AGFI), normed fit index (NFI)) were used to evaluate the fit of the model to the data. The results of the meditational analysis are presented in Figure 2. The overall SEM analysis demonstrated that the persistence meditational model provided an excellent fit to the data: $\chi^{2}(4, N=304)=$ $3.41, p>.05, \mathrm{AGFI}=.98, \mathrm{NFI}=.98$, and $\mathrm{CFI}=1.00$. 


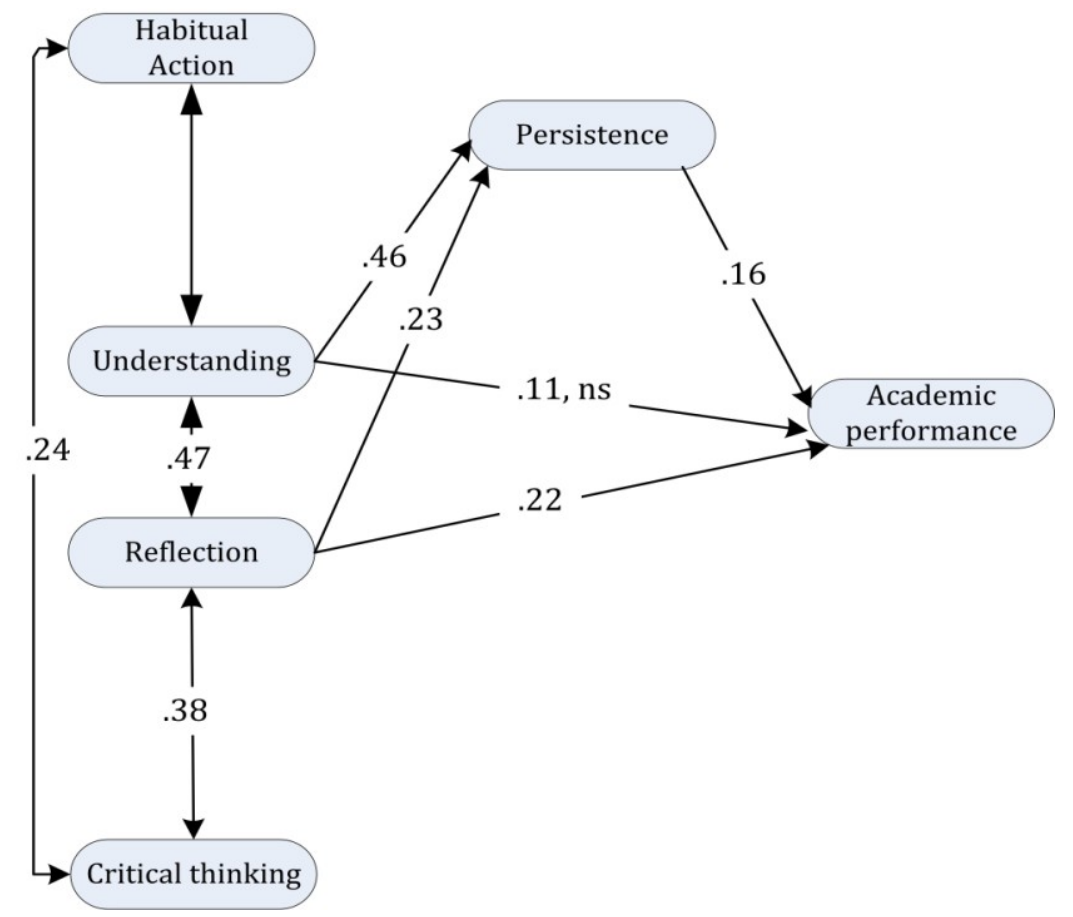

Figure 2. A full structural equation model. Note: $n s=$ nonsignificance, $p>.05$.

\section{Phase 2: Logistic regression analysis}

In the second phase, logistic regression analysis was conducted to assess whether the four predictor variables, gender, understanding, reflection, and critical thinking, significantly predicted whether or not a student would put effort into his/her study. When all four predictors are considered together, they significantly predict whether or not a student would expend effort in his or her study, $\chi^{2}=10.88, d f=4, N=304, p<.05$. Table 2 presents the odds ratios, beta values, and significance level. From the findings noted, we found that only critical thinking was statistically significant as a predictor, $\beta=.78, p=.001, \operatorname{Exp}(\beta)=2.19$. This indicates that the odds of a student answering 'Yes' (that they would expend effort in study), is 2.19 times higher for someone who reports in the engagement of critical thinking.

Table 2. Logistic regression predicting effort

\begin{tabular}{|c|c|c|c|c|c|c|}
\hline \multirow[t]{2}{*}{ Variable } & \multirow[t]{2}{*}{$\beta$} & \multirow[t]{2}{*}{$S E$} & \multirow[t]{2}{*}{ Odds ratio } & \multirow[t]{2}{*}{$p$} & \multicolumn{2}{|c|}{$95 \%$ CI for $\exp \beta$} \\
\hline & & & & & Lower & Upper \\
\hline Gender & -.70 & .65 & .50 & .496 & .14 & 1.77 \\
\hline Understanding & -.04 & .22 & .97 & .868 & .63 & 1.47 \\
\hline Reflection & -.01 & .29 & .99 & .969 & .57 & 1.73 \\
\hline $\begin{array}{l}\text { Critical thin- } \\
\text { king }\end{array}$ & .78 & .25 & 2.19 & .001 & 1.35 & 3.55 \\
\hline Constant & -.23 & 1.90 & .80 & .906 & & \\
\hline
\end{tabular}

Note: $R^{2}=.04$ (Cox \& Snell), .13 (Nagelkerke). Model $\chi^{2}(4)=10.88, p<.05$. Hosmer-Lemeshow Goodness of Fit Test: $\chi^{2}=6.45, d f=8, p=.596$. 


\section{Discussion of findings}

The theoretical frameworks of reflection, disorganization, effort, and persistence have been recognised as determinants of academic performance outcome. A review of the literature suggests that there is an absence of research concerning the relationship between the four phases of reflective thinking (Leung \& Kember, 2003; Mezirow, 1991, 1998) and disorganization, effort, and persistence. The purpose of the current study was to explore within one conceptual model the interrelations between the four theoretical frameworks and students' academic performance in Psychology. In particular, differing from previous research studies (e.g., Phan, 2007, 2008a) we hypothesised that the four phases of reflective thinking would serve as originators of disorganization, effort, and persistence. The evidence (Leung \& Kember, 2003; Phan, 2007) cited previously indicated that the alternative direct-mediating model we hypothesised (Figure 1) was also possible. Furthermore, we also explored whether engagement in reflective thinking practice would lead students to report on the willingness to expend effort in their learning.

Direct relationship: Reflective thinking practice and disorganization, persistence, and effort. The evidence established in this study supports, in part, the hypothesis made concerning the direct relationships between the four phases of reflective thinking and disorganization, persistence, and effort. We found that, in particular, habitual action is related positively to disorganization. Habitual action is concerned with the automatic acquiring of knowledge with very little conscious thought or awareness. Students who possess the habitual action characteristic may lack the necessary and relevant knowledge and motivation that highlight their minimal level of reflective thinking. The characteristics shown from these students may manifest in the forms of disorganization, a lack of motivation, and/or interest in learning. Understanding and reflection also relate positively to persistence. In a similar vein, the reflection phase contributes to the prediction of effort. The understanding phase emphasises students' abilities to acquire knowledge autonomously, and encourages them to persist in their academic learning. This persistence shown may lead, consequently, to students' academic success. In contrast, very much similar to the work of self-efficacy (Bandura, 1986, 1997), students who express characteristics that are habitual action in nature are less likely to demonstrate any resilience in their studying. The reflection and critical thinking phases are much more detailed and complex and require in-depth analysis and understanding of the contents acquired. Students who pursue these two phases of reflective thinking need to invest much more time and 
effort in their studying to ensure that they are effective. It is prudent perhaps, to suggest that both reflection and critical thinking may serve as instruments to assist students in their effort expenditure and learning. The interest to engage in reflection and critical thinking requires dedication, time and, more importantly, the wisdom to question and explore different alternatives and theories. These acts require a serious commitment and a concerted sense of responsibility from students.

Direct relationship: Disorganization, persistence, effort and academic performance. The findings established from hierarchical regression analyses show that students' academic performances were affected by persistence but not by disorganization or effort. This analogous relationship between persistence and academic performance is similar to previous findings (Elliot et al., 1999; Simons et al., 2004). Students who persist, even in the face of obstacles, are more likely to succeed academically. From a teaching and learning perspective, persistence is paramount to successful learning and meaningful engagement. This theoretical and practical position emphasises, in part, the notion of 'hard work' and not ability, and how this stance should be nurtured and encouraged by teachers and educators. By the same token, the importance of persistence has also been emphasised in other motivational-domain areas of research; for example, self-efficacy (see Bandura, 1997; Pajares, 2005; Pajares \& Urdan, 2005) and learning strategies (Elliot et al., 1999; Simons et al., 2004).

A negative relationship between disorganization and academic performance was not established in this study. This absence of significance differs from the work of Elliot et al. (1999), for example, who reported a negative relationship between disorganization and academic performance. Is it possible, perhaps, to argue that there may be other extraneous factors (other than persistence) that could also overcome the influence of disorganization in students' learning? Methodologically, self-report surveys and/or inventories may not accurately portray students' daily study habits. Likewise, cross-sectional data cannot truly capture the ongoing strategies and study habits that students use overtime. Students may overtime develop accurate and preferred strategies and habits that they feel comfortable to help them succeed.

Direct relationship: The four phases of reflective thinking to academic performance. The evidence established, consonant with existing research findings, supports the hypothesis concerning the relationship between the four phases of reflective thinking and students' academic performance in Psychology. Previous studies have reported, for example, the negative effects of habitual action and understanding on academic performance, and the positive ef- 
fects of the reflection and critical thinking phases (Phan, 2007, 2008a). In this study, both understanding and reflection are related significantly to students' performances in Psychology. From a theoretical and practical perspective, students who see learning as having the initiative and capability to reflect, articulate, and to generate new theoretical knowledge are more likely to succeed academically. In contrast, students who view learning as simply having the ability to memorise and to recall factual contents are less successful. The understanding and reflection phases encourage the cultivation of meaningful learning, and the development of specific skills that may lead to mastery learning and academic success. The absence of relationship between critical thinking and academic performance, on the other hand, may be explained in the context of learning objectives and assessment methods. In tertiary institutions, for example, many subject areas and the teaching and assessment procedures that take place do not require or encourage the use of critical thinking. The misalignment and absence thereof in critical thinking may consequently result in a lack of academic performance increase (Phan, 2008b). Similarly, one could argue that in many cases postgraduate teaching (and not undergraduate) emphasises much more mastery learning and critical discourse in knowledge. Future research investigation could explore, for instance, how critical thinking features in postgraduate students' repertoire of knowledge and learning.

Mediating mechanism: Disorganization, persistence, and effort. In line with existing theoretical recommendations for the testing of mediating mechanism (Judd \& Kenny, 1981; Kenny, 2008), we found support for the mediating role of persistence. In particular, results from the present study show the direct-mediating relationship between reflection, persistence and academic performance, and, in part, between understanding, persistence and academic performance. The important emphasis of persistence as a mediator has also been reported in previous research (e.g., Elliot et al., 1999; Simons et al., 2004). Our finding concerning the direct-mediating relationship between the reflection phase, persistence, and academic performance is also different from previous research studies (Phan, 2007, 2008a). In our study, in this case, the reflection phase operates as a direct determinant of persistence and academic performance outcome. Furthermore, persistence is shown to mediate between the reflection phase and academic performance. In previous research, in contrast, the reflection phase was shown to act as a mediator between various motivational variables (e.g., effort) and academic performance. Methodologically, this inconclusive evidence provides a premise for further research investigation into the possible reciprocal effects between the reflection phase, persistence, and academic performance; for example, does persistence cause students to engage in 
reflection, or does reflection lead students to surmount more persistence? It is important, from a practical point of view, that students are encouraged to reflect and to persist in their learning, as these two motivational processes may help to facilitate the success of academic performance outcome. Persistence may serve as a mediating variable that could mediate reflection and other motivational variables (e.g., mastery goals) onto academic performance.

Logistic regression: Reflective thinking practice and effort. Our logistic regression analysis, as a second phase of this study, has provided fruitful information concerning the relationship between reflective practice and effort. Differing from previous research studies (e.g., Elliot et al., 1999; Leung \& Kember, 2003; Phan, 2007, 2008a), we explored whether students' engagement of reflective thinking practice (predominantly involving understanding, reflection, and critical thinking) would lead to a willingness (i.e., a student saying "Yes") in effort expenditure. The findings indicate that, in general, students' engagement in critical thinking is more likely to result in a report of the use of effort in learning. This empirical line of reasoning suggests that more research is needed to explore this complex relationship; for example, under what conditions does a student's critical thinking engagement lead him/her to persevere and to invest more effort in learning? This examination can be made by using qualitative approaches, such as direct questioning and observation (Esterberg, 2002; Padgett, 2004). In a similar vein, an alternative argument can also be made - that is, whether a report in effort expenditure will lead to a student's willingness to engage in critical thinking. These two lines of questioning suggest the possibility, for example, that critical thinking and effort may operate in a reciprocal manner.

\section{Conclusion}

In conclusion, the conceptual model and subsequent findings established in this study make theoretical and practical contributions to the literature concerning the direct-mediating mechanism between reflective thinking practice, disorganization, persistence, effort, and academic performance. Our research investigation is significant as it involved an examination of theoretical orientations within one framework and how they act, in totality, to influence students' academic learning. Reflective thinking practice is an emerging area of interest in education-psychology, as reflected by the recent appearance of a journal entitled Reflective Practice (Phan, 2007), as well as other empirical research that has been conducted so far in different levels of education (e.g., Phan, 2009; Martínez, Farinas, \& Martí, 2008). The importance 
of our research lies in its methodological examination of the four phases of reflection (Leung \& Kember, 2003; Mezirow, 1991; Phan, 2007) as antecedents of effort, disorganization, and persistence and academic performance. Similarly, a statistical examination of disorganization, persistence, and effort as mediators was also involved.

From a practical perspective, educators should view reflective thinking practice as a medium that may serve to advance one's academic performance. From a wider perspective, other than academic skills the practice of reflection also leads to the development of professional skills. The pressing issue then, is what can educators do to encourage the development of reflective thinking practice? It has been suggested, for example, that educators could cultivate reflective thinking practice via means of authentic assessment tasks (e.g., portfolio), and encouraging students to adopt a mastery goal orientation. We note, similarly, whether the DEDEPRO model used in self-regulation (De la Fuente \& Justica, 2007) could also be applied to the teaching of reflective thinking practice. The focus here, according to De la Fuente and Justica (2007), is that educators emphasize on the importance of an interactive process that is part of the teaching and learning processes. By the same token, students should also be encouraged to engage more in effort and persistence as these processes lead, ultimately, to academic success (Elliot et al., 1999; Phan, 2008a; Simons et al., 2004). Methodologically and theoretically, the inquiries examined in this study provide a premise for further research investigation into the practice of reflection and its associated relations with other motivational constructs.

Future research could expand the important objectives that we have identified in this study. For example, the main research interest at present concerns whether the four phases of reflective thinking practice may act as causal determinants of different motivational constructs (e.g., effort, persistence). Statistical interpretations of direct effects and the direction of causality in non-experimental studies are based on theoretical groundings and reflect strong empirical evidence. Methodologically, the use of longitudinal data in conjunction with causal modelling procedures (SEM) offers a stronger premise for making causal inference between reflective thinking practice and the various motivational constructs. In this analysis, we can provide more detailed and enriching information by using longitudinal data that is collected on multiple occasions. In a recent study, for instance, Phan (2008b) used a two-wave panel design to explore the direct and reciprocal relationship between learning approaches and per- 
sonal epistemology. In essence, an important question that exists at present is whether both effort and the critical thinking phase may operate in a reciprocal dynamic system.

Reflective thinking practice is a complex process that cannot be gauged from correlational procedures alone. Qualitative procedures, as used in a number of studies (Chak, 2006; Griffin, 2003) recently, may be more appropriate and could explain the four phases of reflection in-depth. Very few research studies have, for example, explored whether the four phases of reflection situate or develop in sociocultural contexts. One could argue, as indicated by the works of Phan (2007, 2008a; Phan \& Deo, 2007) and others (Mugler \& Landbeck, 1997; Nabobo-Baba, 2006), that the ethos and philosophies of a cultural/ethnic group may influence the nurturing and development of reflective thinking differently. The contextualised nature of the learning environment, as well as the teaching pedagogies and subject contents may in part contribute to the development of this practice. This line of theoretical contention reflects, similarly, the recent works that have attempted to develop students' motivation from sociocultural perspectives (Pressick-Kilborn \& Walker, 2002; Walker, Pressick-Kilborn, Arnold, \& Sainsbury, 2004), as well as the contextualisation of knowledge, knowing and learning (Nabobo-Baba, 2006; Phan \& Deo, 2007). 


\section{References}

Al-Emadi, A. A. (2001). The relationships among achievement, goal orientation, and study strategies. Social Behavior and Personality, 29(8), 823-832.

Bandura, A. (1986). Social foundation of thought and action: A social cognitive theory. Englewood Cliffs, NJ: Prentice-Hall.

Bandura, A. (1997). Self-efficacy: The exercise of control. New York: W. H. Freeman \& Company.

Baron, R. M. \& Kenny, D. A. (1986). The moderator-mediator variable distinction in social psychological research: Conceptual, strategic and statistical considerations. Journal of Personality and Social Psychology, 51, 1173-1182.

Biggs, J. B. (1987). Student approaches to learning. Hawthorn, Victoria: Australian Council for Educational Research.

Biggs, J. (1999). Teaching for quality learning at university. Buckingham, UK: SRHE and Open University Press.

Bouffard, T., Boisvert, J., Vezeau, C., \& Larouche, C. (1995). The impact of goal orientation on self-regulation and performance among college students. British Journal of Educational Psychology, 65, 317-329.

Chak, A. (2006). Reflecting on the self: An experience in a preschool. Reflective Practice, 7, 31-41.

Chou, C. P. \& Bentler, P. M. (1995). Estimates and tests in structural equation modelling. In R. H. Hoyle (Ed.), Structural equation modelling: Concepts, issues, and applications, pp. 37-55. Thousand Oaks, CA: Sage.

Chouinard, R., Karsenti, T., \& Roy, N. (2007). Relations among competence beliefs, utility value, achievement goals, and effort in mathematics. British Journal of Educational Psychology, 77, 501-517.

Cook, T. D. \& Campbell, D. T. (1979). Quasi-experimentation: Design and analysis issues for field settings. Boston, MA: Houghton Mifflin.

De la Fuente, J. \& Justicia, F. (2007). The DEDEPRO Model of regulated teaching and learning: Recent advances. Electronic Journal of Research in Educational Psychology, $5(3), 535-564$. 
Dewey, J. (1933). How we think. Chicago, Henry Regnery.

Dillion, W. R. \& Goldstein, M. (1984). Multivariate analysis, methods and applications. New York: John Wiley.

Dupeyrat, C. \& Mariné, C. (2005). Implicit theories of intelligence, goal orientation, cognitive engagement, and achievement: A test of Dweck's model with returning to school adults. Contemporary Educational Psychology, 30, 43-59.

Elliot, A. J., McGregor, H. A., \& Gable, S. L. (1999). Achievement goals, study strategies, and exam performance: A mediational analysis. Journal of Educational Psychology, $76,628-644$

Entwistle, N. (1988). Motivational factors in students' approaches to learning. In R. Schmeck (Ed.), Learning strategies and learning styles: Perspectives on individual differences, pp. 21-51. New York: Plenum Press.

Esterberg, K. G. (2002). Qualitative methods in social research. Boston: McGraw-Hill.

Fenollar, P., Román, S., \& Cuestas, P. J. (2007). University student's academic performance: An integrative conceptual framework and empirical analysis. British Journal of Educational Psychology, 77, 873-891.

Griffin, M. L. (2003). Using critical incidents to promote and assess reflective thinking preservice teachers. Reflective Practice, 4, 207-220.

Grushka, K., McLeod, J. H., \& Reynolds, R. (2005). Reflecting upon reflection: theory and practice in one Australian University teacher education program. Reflective Practice, $6(2), 239-246$.

Harrison, J. K., Lawson, T. \& Wortley, A. (2005). Mentoring the beginning teacher: developing professional autonomy through critical reflection on practice. Reflective Practice, 6(3), 419-441.

Hoyle, R. \& Panter, A. (1995). Writing about structural equation models. In R. Hoyle (Ed.), Structural equation modelling: Concepts, issues, and applications, pp. 158-176. Thousand Oaks, CA: sage.

Judd, C. \& Kenny, D. (1981). Process analysis: Estimating mediation in treatment evaluations. Evaluation Reviews, 5, 602-619. 
Kember, D., Leung, D., Jones, A., Loke, A. Y., McKay, J., Sinclair, K., Tse, H., Webb, C., Wong, F. K. Y., Wong, M. \& Yeung, E. (2000). Development of a questionnaire to measure the level of reflective thinking. Assessment and Evaluation in Higher Education, 25, 381-389.

Kenny, D. A. (2008). Mediation. Accessed $25^{\text {th }}$ June, 2008, http://davidakenny.net/cm/ mediate.htm

Leung, D. Y. P. \& Kember, D. (2003). The relationship between approaches to learning and reflection upon practice. Educational Psychology, 23(1), 61-71.

Martínez, C. S. M., Farinas, V. J., \& Martí, J. B. (2008). Reflection as a cross competency in psychology studies: Limits and possibilities of virtual environments. Electronic Journal of Research in Educational Psychology, 6(3), 773-792.

Mezirow, J. (1991). Transformative dimensions of adult learning. San Francisco CA: JosseyBass.

Mezirow, J. (1998). On critical reflection. Adult Education Quarterly, 48, 185-198.

Miller, R. B., Greene, B. A., Montalvo, G. P., Ravindran, B., \& Nichols, J. D. (1996). Engagement in academic work: The role of learning goals, future consequences, pleasing others, and perceived ability. Contemporary Educational Psychology, 21, 388-422.

Montoya, R. M. \& Horton, R. S. (2004). On the importance of cognitive evaluation as a determinant of interpersonal attraction. Journal of Personality and Social Psychology, 86(5), 696-712.

Mugler, F. \& Landbeck, R. (1997). Learning in the South Pacific and phenomenography across cultures. Higher Education Research and Development, 16, 227-239.

Nabobo-Baba, U. (2006). Knowing and learning: An indigenous Fijian approach. Institute of Pacific Studies, USP, Suva.

Padgett, D. K. (2004). The qualitative research experience. Belmont, CA: Thomson Brooks/Cole.

Pajares, F. (2005). Self-efficacy during childhood and adolescence. In F. Pajares \& T. Urdan (Eds.), Self-efficacy beliefs during adolescence, pp. 339-367. Greenwich, CT: Information Age Publishing. 
Accessed and retrieved at http:// www.des.emory.edu/mfp/PajaresAdoed2006.pdf on $6^{\text {th }}$ August, 2008.

Pedro, J. Y. (2005). Reflection in teacher education: exploring pre-service teachers' meanings of reflective practice. Reflective Practice, 6(1), 49-66.

Phan, H. P. (2007). Examination of student learning approaches, reflective thinking, and selfefficacy beliefs at the University of the South Pacific: A path analysis. Educational Psychology, 27(6), 789-806.

Phan, H. P. (2008a). Unifying different theories of learning: Theoretical framework and empirical evidence. Educational Psychology, 28(3), 325-340.

Phan, H. P. (2008b). Predicting change in epistemological beliefs, reflective thinking and learning styles: A longitudinal study. British Journal of Educational Psychology, 78, 75-93.

Phan, H. P. (2009). Exploring students' reflective thinking practice, deep processing strategies, effort, and achievement goal orientations. Educational Psychology, 29(3), 297-313.

Phan, H. P. \& Deo, B. (2007). The revised learning process questionnaire: A validation of a Western model of students' study approaches to the South Pacific context using confirmatory factor analysis. British Journal of Educational Psychology, 77, 719-739.

Pintrich, P. R. (1989). The dynamic interplay of student motivation and cognition in the college classroom. In M. Maehr \& C. Ames (Eds.), Advances in motivation and achievement: Motivation-enhancing environments, Vol. 6_pp. 117-160). Greenwich, CT: JAI Press.

Pintrich, P. R., Smith, D., Garcia, T., \& McKeachie, W. J. (1991). A manual of the Motivated Strategies for Learning Questionnaire (MSLQ). National Center for Research to Improve Postsecondary Teaching and Learning. Ann Arbor: University of Michigan.

Pintrich, P. R., Smith, D., Garcia, T., \& McKeachie, W. J. (1993). Reliability and predictive validity of the Motivated Strategies for Learning Questionnaire (MSLQ). Educational and Psychological Measurement, 53, 801-813.

Pressick-Kilborn, K. \& Walker, R. (2002). The social construction of interest in a learning community. In D. McInerney \& S. Van Etten (Eds.), Research on sociocultural influences on motivation and learning, pp. 153-182. Greenwich, CT: Information Age Publishing. 
Simons, J., Dewitte, S., \& Lens, W. (2004). The role of different types of instrumentality in motivation, study strategies, and performance: Know why you learn, so you'll know what you learn! British Journal of Educational Psychology, 74, 343-360.

Sobel, M. E. (1982). Asymptotic confidence intervals for indirect effects in structural equation models. In S. Leinhardt (Ed.), Sociological methodology 1982, pp. 290-312. Washington DC: American Sociological Association.

Walker, R. A., Pressick-Kilborn, K., Arnold, L. S., \& Sainsbury, E. J. (2004). Investigating motivation in context: Developing sociocultural perspectives. European Psychologist, 9, 245-256.

Wentzel, K. R. (1996). Social and academic motivation in middle school: Concurrent and long-term relations to academic effort. Journal of Early Adolescence, 16, 390-406.

Yanchar, S. C., Slife, B. D., \& Warne, R. (2008). Critical thinking as disciplinary practice. Review of General Psychology, 12(3), 265-281.

Zimmerman, B. J. \& Risemberg, R. (1997). Self-regulatory dimensions of academic learning and motivation. In G. Phye (Ed.), Handbook of academic learning, pp. 105-125. New York: Academic Press. 